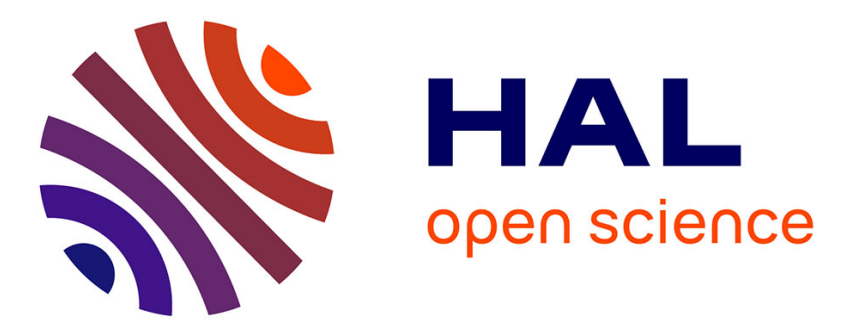

\title{
Unique Bonding Nature of Carbon-Substituted Be2 Dimer inside the Carbon (sp2) Network
}

Rafal Roszak, Szczepan Roszak, D. Majumdar, Lucyna Firlej, Bogdan

Kuchta, Jerzy Leszczynski

\section{- To cite this version:}

Rafal Roszak, Szczepan Roszak, D. Majumdar, Lucyna Firlej, Bogdan Kuchta, et al.. Unique Bonding Nature of Carbon-Substituted Be2 Dimer inside the Carbon (sp2) Network. Journal of Physical Chemistry A, 2014, 118 (30), pp.5727-5733. 10.1021/jp504618h . hal-01937956

\section{HAL Id: hal-01937956 https://hal.science/hal-01937956}

Submitted on 22 Sep 2021

HAL is a multi-disciplinary open access archive for the deposit and dissemination of scientific research documents, whether they are published or not. The documents may come from teaching and research institutions in France or abroad, or from public or private research centers.
L'archive ouverte pluridisciplinaire HAL, est destinée au dépôt et à la diffusion de documents scientifiques de niveau recherche, publiés ou non, émanant des établissements d'enseignement et de recherche français ou étrangers, des laboratoires publics ou privés.

\section{(c)(1)}

Distributed under a Creative Commons Attribution| 4.0 International License 


\title{
Unique Bonding Nature of Carbon-Substituted $\mathrm{Be}_{2}$ Dimer inside the Carbon $\left(\mathbf{s p}^{2}\right)$ Network
}

\author{
Rafal Roszak, ${ }^{\dagger \dagger}$ Szczepan Roszak, ${ }^{* \dagger, \dagger}$ D. Majumdar, ${ }^{* \dagger}$ Lucyna Firlej, ${ }^{\S}$ Bogdan Kuchta, \\ and Jerzy Leszczynski* ${ }^{* \dagger}$ \\ ${ }^{\dagger}$ Interdisciplinary Center for Nanotoxicity, Jackson State University, Jackson, Mississippi 39217, United States \\ ${ }^{\ddagger}$ Institute of Physical and Theoretical Chemistry, Wroclaw University of Technology, Wybrzeze Wyspianskiego 27, 50-370 Wroclaw, \\ Poland \\ ${ }^{\S}$ Laboratoire Charles Coulombs, Universite Montpellier 2, 34095 Montpellier, France \\ "Laboratoire MADIREL, Universite Aix-Marseille, 13396 Marseille, France
}

\begin{abstract}
Controlled doping of active carbon materials (viz., graphenes, carbon nanotubes etc.) may lead to the enhancement of their desired properties. The least studied case of $\mathrm{C} / \mathrm{Be}$ substitution offers an attractive possibility in this respect. The interactions of $\mathrm{Be}_{2}$ with $\mathrm{Be}$ or $\mathrm{C}$ atoms are dominated by the large repulsive Pauli exchange contributions, which in turn offsets the attractive interactions leading to relatively small binding energies. The $\mathrm{Be}_{2}$ dimer, e.g., after being doped inside a planar carbon network, undergoes orbital adjustments due to charge transfer and unusual intermolecular interactions and is oriented perpendicular to the plane of the carbon network with the $\mathrm{Be}-\mathrm{Be}$ bond center located inside the plane. The present theoretical

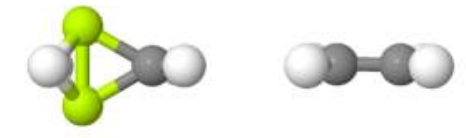
investigation on the nature of bonding in $\mathrm{C} / \mathrm{Be}_{2}$ exchange complexes, using state of the art quantum chemical techniques, reveals a sp ${ }^{2}$ carbon-like bonding scheme in $\mathrm{Be}_{2}$ arising due to the molecular hybridization of $\sigma$ and two $\pi$ orbitals. The perturbations imposed by doped $\mathrm{Be}_{2}$ dimers exhibit a local character of the structural and electronic properties of the complexes, and the separation by two carbon atoms between beryllium active centers is sufficient to consider these centers as independent sites.
\end{abstract}

\section{INTRODUCTION}

The beryllium compounds are probably the least studied substances containing the second row elements. ${ }^{1}$ Despite their unique chemical properties, not much work has been done so far to use such properties for practical applications. Part of the problem is due to the toxicity of the metal. There is also sufficient evidence for the carcinogenic properties of beryllium compounds causing lung cancer. ${ }^{2}$ Beryllium, as one of the lightest atoms, on the other hand, offers an interesting possibility to functionalize carbon materials through carbon substitution. The carbon substitution by lithium, boron, nitrogen, and oxygen or their addition inside the carbon networks was extensively studied with the aim to replace heavy metals as catalysts. ${ }^{3}$ The beryllium atom as well as beryllium dimer are interesting alternatives in search of new nanomaterials due to their unusual chemistry. For example, some of these $\mathrm{Be}$-containing materials are promising alternatives for hydrogen storage media. Several microporous coordination polymers (MCPs) with Be-based secondary building units and metal organic framework (MOF) were synthesized with favorable adsorbent properties. ${ }^{4-6}$ The direct Be substitution was also suggested as an efficient way to improve hydrogen adsorption. ${ }^{7}$ There are two important bonds in such Be-substituted carbon networks that modulate their adsorption properties, viz. $\mathrm{Be}-\mathrm{C}$ and $\mathrm{Be}-\mathrm{Be}$ bonds. The $\mathrm{Be}-\mathrm{C}$ bonding properties are not well studied so far, although a range of organoberyllium compounds are synthesized. ${ }^{8-10}$ On the contrary, the $\mathrm{Be}-\mathrm{Be}$ bond has drawn constant interest due to its unusual bonding properties. ${ }^{11}$ The unusual character of beryllium compounds may be demonstrated from the properties of the $\mathrm{Be}_{2}$ dimer. The dissociation energy of $\mathrm{Be}_{2}(2.66 \mathrm{kcal} / \mathrm{mol})^{11}$ is an order smaller than the corresponding energy of covalently bonded dimer $\mathrm{Li}_{2}$ $(24.3 \mathrm{kcal} / \mathrm{mol}){ }^{12}$ suggesting weak van der Waals type interactions in $\mathrm{Be}_{2}$. The unusual nature of $\mathrm{Be}_{2}$ dimer is further demonstrated in the bond distance of $\mathrm{Be}_{2}$ dimer. The $\mathrm{Be}-\mathrm{Be}$ bond distance $(2.54 \AA)^{11}$ is shorter than that of $\mathrm{Li}_{2}(2.67 \AA)$ and also much shorter than weakly bonded $\mathrm{Ne}_{2}(3.10 \AA)^{13}$ (characterized by typical nonbonding interactions of $0.08 \mathrm{kcal} /$ $\mathrm{mol}$ ). The bond distance of $\mathrm{Be}_{2}$ shows that the dimer may be classified as one possessing significant covalent contribution, although energetically it is far from chemical bond characteristics of second row dimers viz. $\mathrm{B}_{2}\left(R_{\mathrm{e}}=1.59 \AA\right.$, $D_{\mathrm{o}}=69.3 \mathrm{kcal} /$ mol). ${ }^{14}$

The interaction with the third body (atom or molecular fragment) drastically changes the properties of $\mathrm{Be}_{2}$ with severalfold increase of bonding energy. This phenomenon was 
Table 1. Molecular Orbitals Involved in the Binding in $\mathrm{Be}_{2}, \mathrm{Be}_{3}$, and $\mathrm{Be}_{2} \mathrm{C}$

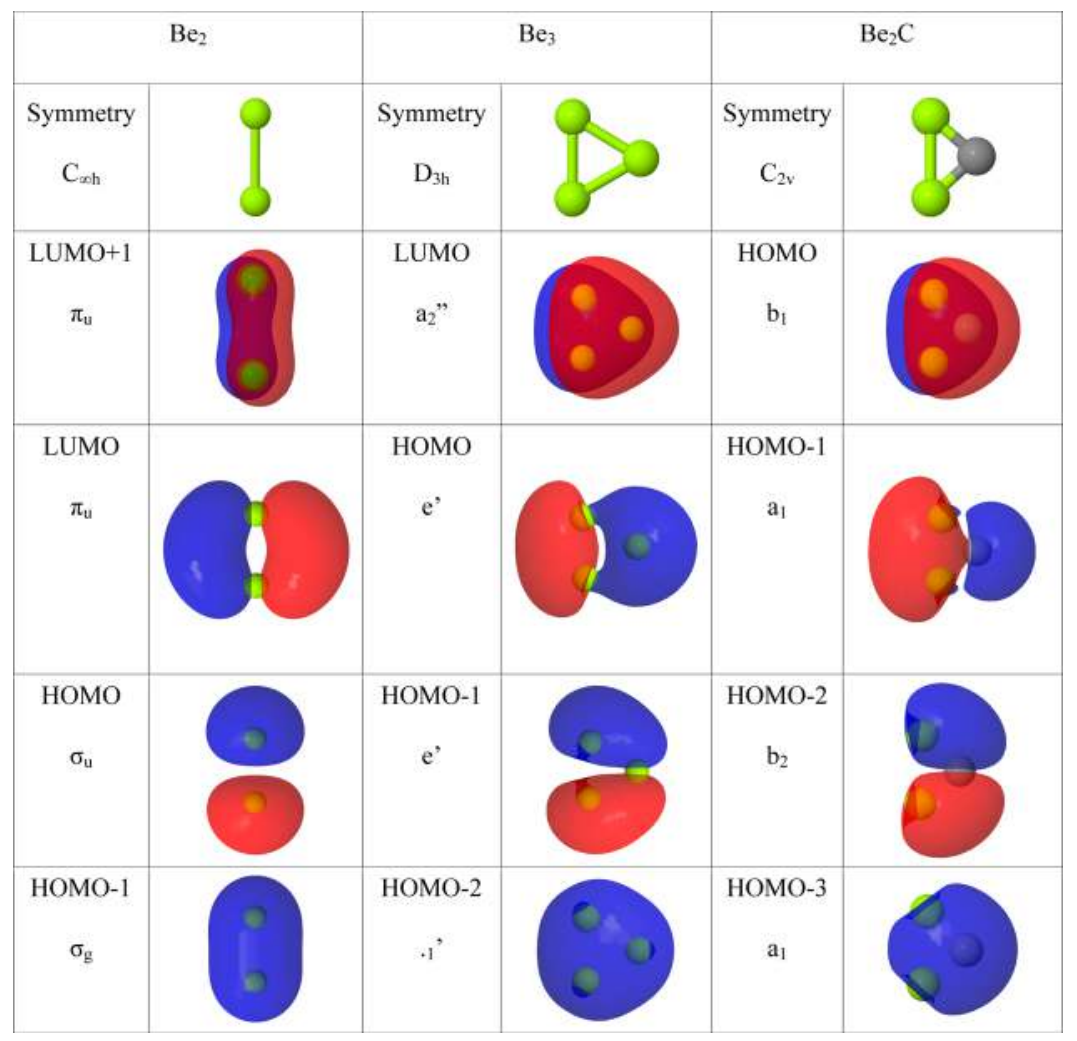

observed in the case of $\mathrm{Be}_{3}$ ( $\mathrm{Be}$ atom as a third body) and $\mathrm{Be}_{2} \mathrm{C}$ ( $\mathrm{C}$ as the third body). ${ }^{15}$ The $\mathrm{Be}_{2}$ dimer, as a closed shell $\sigma_{\mathrm{g}}{ }^{2} \sigma_{\mathrm{u}}{ }^{2}$ complex of two interacting $\mathrm{Be}\left({ }^{1} \mathrm{~S}\right)$ atoms, is stabilized by the correlation energy due to low-energy $2 p$ beryllium orbitals. The electronic ground state for $\mathrm{Be}_{2}$ of $\mathrm{X}^{1} \Sigma_{\mathrm{g}}^{+}$with the $\sigma_{\mathrm{g}}^{2} \sigma_{\mathrm{u}}^{2}$ configuration is accompanied by two deep low-lying excited electronic states: $1^{3} \Sigma_{\mathrm{u}}{ }^{+}$with the $\sigma_{\mathrm{g}}{ }^{2} \sigma_{\mathrm{u}} \sigma_{\mathrm{g}}{ }^{\prime}$ configuration $\left(T_{\mathrm{e}}=0.9\right.$ $\mathrm{eV} ; T_{\mathrm{e}}$ is the transition energy from the ground to the desired excited state) and $1^{3} \Pi_{\mathrm{g}}^{+}$resulting from $\sigma_{\mathrm{g}}^{2} \sigma_{\mathrm{u}} \pi_{\mathrm{u}}$ configuration $\left(T_{\mathrm{e}}=1.08 \mathrm{eV}\right) .{ }^{11}$ These configurations are isoelectronic with carbon possessing ground ${ }^{3} \mathrm{P}\left(2 \mathrm{~s}^{2} 2 \mathrm{p}^{2}\right)$, and low-lying excited ${ }^{1} \mathrm{D}$ and ${ }^{1} \mathrm{~S}$ electronic states. Additionally, $T_{\mathrm{e}}$ 's between similar electronic states of $\mathrm{C}\left(1.263 \mathrm{eV}\right.$ for the $\mathrm{C}\left({ }^{3} \mathrm{P}\right)$ to $\mathrm{C}\left({ }^{1} \mathrm{D}\right)$ transition) and $\mathrm{Be}_{2}$ are alike. ${ }^{16}$

The aim of this work is to determine the properties of the $\mathrm{Be}_{2}$ dimer fragment after the substitution of a single carbon atom (by $\mathrm{Be}_{2}$ dimer) in the $\mathrm{sp}^{2}$ carbon network. The interactions of $\mathrm{Be}_{2}$ with the rest of the system (the third body) modify its properties and impart new chemical properties to this center. Structures as well as the nature of bonding are being investigated using state of the art quantum chemical techniques. The newly evolved bonding characteristics of the $\mathrm{Be}_{2}$ fragment in $\mathrm{Be}_{3}, \mathrm{Be}_{2} \mathrm{C}, \mathrm{CH}_{2} \mathrm{Be}_{2} \mathrm{H}_{2}$ (ethylene derivative), substituted aromatic compounds (benzene and naphthalene), and modified extended carbon materials (ovalene) was investigated. The computed geometric, orbital properties, charge distribution, and interaction energy decomposition results were not only found to be useful to enhance the present knowledge on $\mathrm{Be}-\mathrm{Be}$ and $\mathrm{Be}-\mathrm{C}$ chemical bonds but also could be used to predict the special chemical behavior of the Be center.

\section{METHODS OF COMPUTATION}

The computation of structural parameters of small molecules $\left(\mathrm{Be}_{2}, \mathrm{Be}_{3}, \mathrm{Be}_{2} \mathrm{C}\right.$, and ethylene derivatives) were carried out using the Møller-Plesset second-order perturbation (MP2) methodology ${ }^{17}$ with the aug-cc-pVTZ basis set for atoms. ${ }^{18}$ For benzene and naphthalene derivatives the basis set was reduced to aug-cc-pVDZ. ${ }^{19}$ The optimizations of Be doped ovalene $\left(\mathrm{C}_{32} \mathrm{H}_{14}\right)$ structures were carried out at the density functional theory (DFT) ${ }^{20}$ level using the B3LYP functional. ${ }^{21-23}$ The test DFT calculations for smaller systems indicates that the method preserves the features observed at the MP2 studies. No symmetry constraints were imposed during the geometry optimizations. However, to model the planar extended structures, the position of the external ring was frozen in the geometry of $\mathrm{C}_{32} \mathrm{H}_{14}$. The computed energy values were further refined using single-point MP2-level energy calculations on the optimized structures with cc-pvdz basis set of atoms.

A hybrid variational-perturbational interaction energy decomposition scheme ${ }^{24}$ was used to compute contributions of various energy terms in such interactions. The SCF interaction energy $\left(\Delta E^{\mathrm{HF}}\right)$ is partitioned into first-order electrostatic $\left(\varepsilon_{\mathrm{el}}^{(10)}\right)$, Heitler-London exchange $\left(\varepsilon_{\mathrm{ex}}^{(10)}\right)$, and higher order delocalization $\left(\Delta E_{\mathrm{del}}^{\mathrm{HF}}\right)$ energy terms.

$$
\Delta E^{\mathrm{HF}}=\varepsilon_{\mathrm{el}}^{(10)}+\varepsilon_{\mathrm{ex}}^{\mathrm{HL}}+\Delta E_{\mathrm{del}}^{\mathrm{HF}}
$$

The electron correlation effects are taken into account by means of the MP2 theory. The $\varepsilon_{\mathrm{MP}}^{(2)}$ interaction energy term, which includes the dispersion and correlation contributions to the Hartree-Fock components, is calculated in the supermolecular approach as the difference of MP2 energy corrections of the supermolecule and the monomers (eq 2).

$$
\varepsilon_{\mathrm{MP}}^{(2)}=E_{\mathrm{AB}}^{(2)}-E_{\mathrm{A}}^{(2)}-E_{\mathrm{B}}^{(2)}
$$


The energy terms on the right-hand side of eq 2 represent the difference between the MP2 and Hartree-Fock energies of the supermolecule $(\mathrm{AB})$ and the monomers (A and $\mathrm{B})$.

All the interaction energy terms are calculated consistently in the dimer-centered basis set and are therefore free from the basis set superposition error due to the full counterpoise correction. $^{25}$ The dispersion energy was also calculated directly by applying the expression for the second-order energy $\varepsilon_{\text {disp }}^{(20)}$. The atomic charges were computed using natural bond orbital $(\mathrm{NBO}){ }^{26}$

The geometry optimization calculations at MP2 and DFT/ B3LYP were carried out using the Gaussian-09 code. ${ }^{27}$ The interaction energy decomposition scheme implemented in the GAMESS code ${ }^{28}$ was used for energy partitioning. ${ }^{29}$ The molecular graphics have been generated using Jmol software. ${ }^{30}$

\section{RESULTS AND DISCUSSION}

a. $\mathrm{Be}_{3}$ Bonding Properties. The $\mathrm{Be}_{2}$ dimer is a weak complex due to interactions of closed $2 \mathrm{~s}$ valence-shells of $\mathrm{Be}$ atoms. The third body, in the form of an additional beryllium atom, changes the orbital space organization and interactions lead to the $D_{3 h}$ triangle geometry of $\mathrm{Be}_{3}$ with the significant dissociation energy. The $\mathrm{Be}-\mathrm{Be}$ distance is reduced from 2.54 to $2.22 \AA^{11}$ due to such interactions. The inspection of molecular orbitals (MOs) indicates that the $\mathrm{MO}$ picture interpreted as a complex of $\mathrm{Be}_{2}$ dimer and $\mathrm{Be}$ atom does not dramatically change the topological features. The $\sigma_{\mathrm{g}} \sigma_{\mathrm{u}} \pi_{\mathrm{u}}$ orbitals of dimer could be easily projected onto three occupied orbitals $\left(\mathrm{a}_{1}{ }^{\prime}, \mathrm{e}^{\prime}, \mathrm{e}^{\prime}\right)$ of the trimer (Table 1$)$. The low-lying virtual $\pi_{\mathrm{u}}$ orbital, being transformed into $\mathrm{a}_{2}{ }^{\prime \prime}$ within the $D_{3 h}$ symmetry representation, does not directly take part in the bonding at the HF level. However, this effect significantly stabilizes the beryllium trimer when the correlation energy is included.

$$
\begin{aligned}
& \Psi_{4}\left(\mathrm{a}_{1}^{\prime}\right)=2 \mathrm{~s}\left(\mathrm{Be}_{1}\right)+2 \mathrm{~s}\left(\mathrm{Be}_{2}\right)+2 \mathrm{~s}\left(\mathrm{Be}_{3}\right) \\
& \Psi_{5}\left(\mathrm{e}^{\prime}\right)=2 \mathrm{p}_{x}\left(\mathrm{Be}_{1}\right)+2 \mathrm{~s}\left(\mathrm{Be}_{2}\right)-2 \mathrm{~s}\left(\mathrm{Be}_{3}\right) \\
& \Psi_{6}\left(\mathrm{e}^{\prime}\right)=2 \mathrm{~s}\left(\mathrm{Be}_{1}\right)+\left[2 \mathrm{p}_{y}-2 \mathrm{~s}\right]\left(\mathrm{Be}_{2}\right)+\left[2 \mathrm{p}_{y}-2 \mathrm{~s}\right]\left(\mathrm{Be}_{3}\right)
\end{aligned}
$$

The simplified molecular orbital composition of valence atomic components (eq 3), in contrast to the beryllium dimer, indicates the increasing role of atomic p orbitals. They are responsible for significant covalent bond contribution in the bonding.

The interaction energy decomposition for the $\mathrm{Be}_{2}+\mathrm{Be}$ system indicates the high values of interaction energy components compared to the total interaction energy. The attractive interaction energy terms offset the extremely high exchange repulsion contribution $\varepsilon_{\mathrm{ex}}^{\mathrm{HL}}$ (Table 2), resulting in small bonding energy. The delocalization energy $\Delta E_{\mathrm{del}}^{\mathrm{HF}}$ (responsible for induction interactions) constitutes the largest attraction term. It is totally quenched by the exchange interaction energy. The electrostatic $\varepsilon_{\mathrm{el}}^{(10)}$ and dispersion energies $\varepsilon_{\text {disp }}^{(20)}$, although smaller in value, are very important in the final balance of bonding energy. The results of the interaction energy partitioning thus indicate the importance of covalent forces to the overall bonding mechanism. The large values of energy components canceling the small total interaction energy constitutes a major characteristic feature of molecular bonding of Be clusters. The large and dominating
Table 2. Interaction Energy Decomposition Terms for $\mathrm{Be}_{2}$, $\mathrm{Be}_{3}$, and $\mathrm{Be}_{2} \mathrm{C}$ Interacting Complexes (Energies in $\mathrm{kcal} / \mathrm{mol}$ )

$\begin{array}{cccc} & \mathrm{Be}_{2} & \mathrm{Be}_{3} & \mathrm{Be}_{2} \mathrm{C} \\ \text { interacting fragments } & \mathrm{Be}+\mathrm{Be} & \mathrm{Be}_{2}+\mathrm{Be} & \mathrm{Be}_{2}+\mathrm{C}\left({ }^{1} \mathrm{~S}\right) \\ \varepsilon_{\mathrm{el}}^{(10)} & -10.0 & -43.7 & -205.1 \\ \varepsilon_{\mathrm{ex}}^{\mathrm{HF}} & 24.8 & 104.0 & 486.9 \\ \Delta E_{\mathrm{del}}^{\mathrm{HF}} & -10.6 & -72.2 & -363.7 \\ \Delta E^{\mathrm{HF}} & 4.2 & -11.8 & -81.8 \\ \varepsilon_{\mathrm{dis}}^{(20)} & -7.7 & -28.3 & -59.1 \\ \varepsilon_{\mathrm{MP}}^{(2)} & -5.1 & -30.3 & -28.3 \\ \Delta E^{\mathrm{MP} 2} & -0.9 & -21.8 & -110.1 \\ \Delta E^{\mathrm{CCSD}(\mathrm{T})} & -0.9 & -21.7 & -145.7\end{array}$

Pauli exchange repulsion term canceling attractive contributions is also a typical characteristics for the $\mathrm{Be}-\mathrm{Be}$ bonding.

b. Nature of the Chemical Bond in the $\mathrm{Be}_{2} \mathrm{C}$ Complex. The $\mathrm{Be}_{2} \mathrm{C}$ complex is formed with an atomization energy of $129.1 \mathrm{kcal} / \mathrm{mol}$. The lowest energy structure of the ${ }^{1} \mathrm{~A}_{1}\left(C_{2 v}\right.$ symmetry) electronic state possesses the $\mathrm{T}$-shaped geometry and is characterized by Be-Be: $2.117 \AA$ and Be-C: $1.584 \AA$ bond distances. These results are in good agreement with extended $\operatorname{CCSD}(\mathrm{T})(2.068$ and $1.598 \AA$ ) $)$ and CASSCF $(2.087$ $\AA$ and1.607 $\AA$ ) calculations. ${ }^{11}$ It is to be noted that the inclusion of electronic correlation is essential for the proper determination of the electronic ground state structure. The lower level of theory leads to the wrong prediction of geometry of the ground electronic state. ${ }^{11-13}$ The $\mathrm{Be}-\mathrm{Be}$ bond in $\mathrm{Be}_{2} \mathrm{C}$ is much shorter than the one in the $\mathrm{Be}_{2}$ dimer; however, the composition and topology of the orbitals are preserved (compared to the $\mathrm{Be}_{2}$ dimer) and are well visible as molecular orbital components of $\mathrm{Be}_{2} \mathrm{C}$. The $\sigma_{\mathrm{g}}, \sigma_{\mathrm{w}}, \pi_{\mathrm{w}}$ and $\pi_{\mathrm{u}}{ }^{\prime}$ orbitals of the $\mathrm{Be}_{2}$ fragment form MOs with $2 \mathrm{~s}, 2 \mathrm{p}_{x}, 2 \mathrm{p}_{y}$, and $2 \mathrm{p}_{z}$, of carbon, respectively (Table 1). The HOMO of $\pi$ character stabilizes the structure by forming three center-two electron (3c2e) delocalized bond. The other bonds are also delocalized and cover the whole molecule. The NBO atomic charges (C: -1.611 ; Be 0.805 electron) indicate atomic charge separation in the molecule. The $\mathrm{Be}-\mathrm{Be}$ distance in $\mathrm{Be}_{2} \mathrm{C}$ correlates with $\mathrm{Be}_{2}{ }^{+}$ $(2.211 \AA)$ rather than $\mathrm{Be}_{2}(2.54 \AA) .{ }^{11}$ This confirms that the computed charge distribution pattern leads to significant ionic contribution to the $\mathrm{C}-\mathrm{Be}$ bond. Similar to the $\mathrm{Be}_{3}$ case, the intermolecular interactions are dominated by the exchange repulsion term $\varepsilon_{\mathrm{ex}}^{\mathrm{HL}}($ Table 2$)$. The largest attractive contribution is of induction origin $\left(\Delta E_{\mathrm{del}}^{\mathrm{HF}}\right.$, delocalization term); however, the electrostatic contribution is also significant. The absolute values of interaction energy contributions are large with respect to the total Hartree-Fock (HF) interaction energy. It is an indication that chemical manipulation on the bonding properties will greatly influence the final energy. The already attractive HF energy is further enhanced by the correlation contribution.

c. Ethylene vs $\mathrm{CH}_{2} \mathrm{Be}_{2} \mathrm{H}_{2}$ Derivative. The structure of the $\mathrm{CH}_{2} \mathrm{Be}_{2} \mathrm{H}_{2}$ complex matches closely with $\mathrm{CH}_{2} \mathrm{CH}_{2}$. The $\mathrm{Be}-\mathrm{Be}$ axis is perpendicular to the ideal plane defined by carbon and hydrogen atoms and the midpoint $\mathrm{X}$ of the $\mathrm{Be}-\mathrm{Be}$ bond (Figure 1S, Supporting Information). The molecular orbital pictures of substituted ethylene and its parent molecule are very similar (Table 3 ) with the HOMO having $\pi$ character. The perturbations in the ethylene skeleton, imposed by the $\mathrm{C} / \mathrm{Be}_{2}$ substitution, do not change the basic topological features of the MOs and the correspondence between the orbitals is obvious and easily tractable within the $D_{2 h}$ to $C_{2 v}$ transformation (Table 
Table 3. Valence Molecular Orbitals for $\mathrm{CH}_{2} \mathrm{Be}_{2} \mathrm{H}_{2}$ Complex and Complementary Ethylene Molecules

\begin{tabular}{|c|c|c|}
\hline Symmetry & Symmetry \\
\hline HOMO & POMO \\
\hline $\mathrm{b}_{2}$ & \\
\hline
\end{tabular}

3). The $\mathrm{XH}_{2}$ angle $\left(114.9^{\circ}\right)$ is very close to one in the complementary $-\mathrm{CH}_{2}$ fragment $\left(111.2^{\circ}\right)$ and in ethylene $\left(117.4^{\circ}\right)$. The orbitals in the valence space of the $\mathrm{Be}_{2}$ dimer in the complex $\left(\sigma_{\mathrm{g}}, \sigma_{\mathrm{u}}, \pi_{\mathrm{u}}, \pi_{\mathrm{u}}^{\prime}\right)$ transform from $\sigma_{\mathrm{u}}, \pi_{\mathrm{w}}, \pi_{\mathrm{u}}^{\prime}$ into the $\sigma \pi^{2}$ configuration (Figure 1). This transformation is analogous to the hybridization of $2 \mathrm{~s}, 2 \mathrm{p}_{x}, 2 \mathrm{p}_{y}$ atomic orbitals in carbon. The $\sigma_{\mathrm{u}}$ orbital, not involved in the hybridization, corresponds to the orthogonal $\mathrm{p}_{z}$ orbital in the $\mathrm{sp}^{2}$-hybridized carbon. The center of molecular hybrids $\left(\sigma \pi^{2}\right)$ is located at the midpoint $\mathrm{X}$ of the $\mathrm{Be}-\mathrm{Be}$ bond. The additional $\sigma_{\mathrm{g}}$ (LUMO) is not included

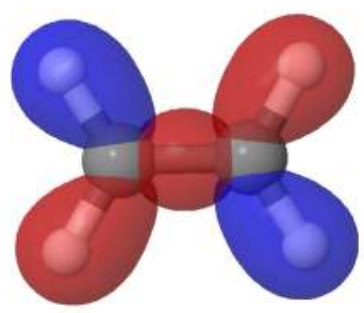

a

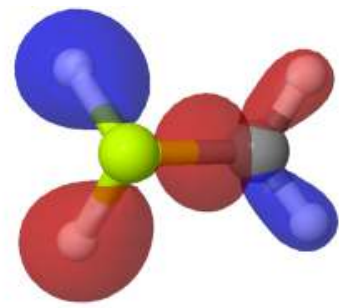

b
Figure 1. Ethylene and $\mathrm{C}_{2} \mathrm{Be}_{2} \mathrm{H}_{2}$ combined HOMO $\sigma$ orbitals corresponding to the $\mathrm{sp}^{2}$ hybridization $\left(\sigma \pi^{2}\right.$ in case of beryllium derivative): (a) ethylene $b_{3 g}, a_{1}, b_{1 u}$; (b) $\mathrm{C}_{2} \mathrm{Be}_{2} \mathrm{H}_{2} b_{2}, a_{1}, a_{1}$. in the bonding scheme and constitutes the reactive orbital on the $\mathrm{Be}-\mathrm{Be}$ axis with no analogue available in pure ethylene. Due to the substitution, the character of double $\mathrm{C}=\mathrm{C}$ bond is preserved and in the $\mathrm{X}=\mathrm{C}$ case is represented by $\pi\left(\mathrm{b}_{3 \mathrm{u}} \rightarrow \mathrm{b}_{1}\right)$ and $\sigma\left(\mathrm{a}_{\mathrm{g}} \rightarrow \mathrm{a}_{1}\right)$ orbitals.

The electronic population analysis, due to the delocalized character of molecular orbitals, is very sensitive to the method of computation. The NBO population analysis indicates the local character of perturbation associated with the $\mathrm{C} / \mathrm{Be}_{2}$ substitution. The charges on hydrogens in the $\mathrm{CH}_{2}$ group are similar to that in the ethylene case (Figure 1S, Supporting Information). The value of $-\mathrm{Be}_{2} \mathrm{H}_{2}$ to $-\mathrm{CH}_{2}$ charge transfer $(-0.924$ electron $)$ should be treated with a caution considering the rather low dipole moment of the molecule of $2.323 \mathrm{D}$. The much shorter $\mathrm{Be}-\mathrm{Be}$ distance of $1.718 \AA$ with respect to the $\mathrm{Be}_{2}$ dimer $(2.54 \AA)$ and $\mathrm{Be}_{2}^{+}$cation $(2.11 \AA$ ) indicates large involvement of beryllium atoms in the bonding mechanism. The very short $\mathrm{Be}-\mathrm{Be}$ distance compares well with deeply bound excited states of $\mathrm{Be}_{2}{ }^{+}$and suggests the importance of contribution from low-lying electronic states to the bonding in studied systems. $^{31,32}$

d. Substituted Aromatic Systems. The $\mathrm{C} / \mathrm{Be}_{2}$ and (C/ $\left.\mathrm{Be}_{2}\right)_{2}$ substitutions were studied in benzene and naphthalene. In all the cases, substitution leads to the same structural 
modification preserving the planar ring, and the $\mathrm{Be}_{2}$ axis being perpendicular to the plane of the complex (Figure 2). The
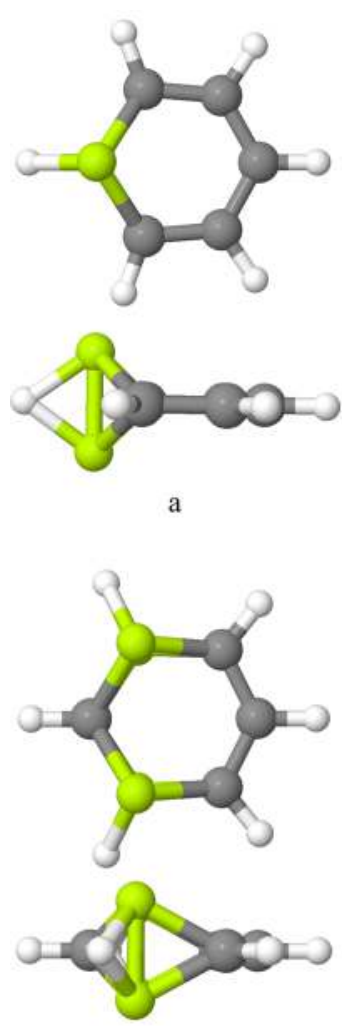

c

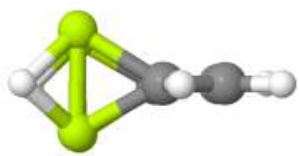

b

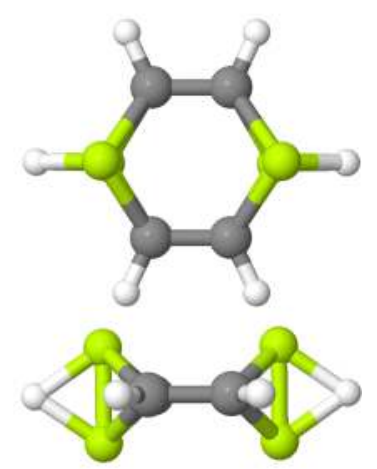

d

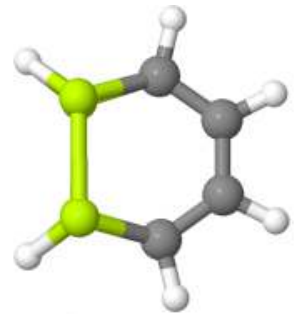

Figure 2. Top and side views of single (a) and double ((b) ortho, (c) meta, (d) para) $\mathrm{Be}_{2}$ derivatives of benzene.

midpoint $(\mathrm{X})$ of the $\mathrm{Be}-\mathrm{Be}$ bond lies inside the plane of the ring and constitutes the center of the orbitals related to $\mathrm{Be}_{2}$ bonding. The hydrogen atom closest to $\mathrm{Be}_{2}$, complements the skeleton of the parent benzene molecule. The $\mathrm{Be}-\mathrm{Be}$ distance in all the studied structures is close to $1.7 \AA$, indicating a similarity of ethylene involvement in $\mathrm{Be}_{2}$ in bonding. The molecular orbital picture corresponds to the proposed molecular model of $\sigma \pi^{2}$ hybridization (Figure 3 ). The

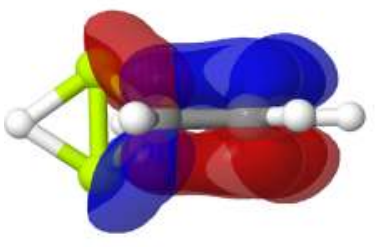

a

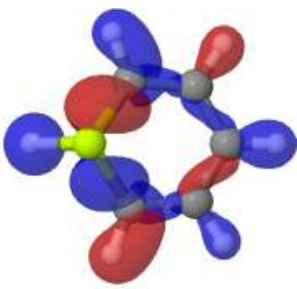

b

Figure 3. Combined (a) three HOMO $\pi$ orbitals (side view) and (b) three HOMO $\sigma$ orbitals covering the beryllium bond in the plane of the molecular ring (top view) in $\mathrm{C}_{5} \mathrm{Be}_{2} \mathrm{H}_{6}$ benzene derivative.

combined picture of three molecular orbitals located in the plane of carbon skeleton (Figure 3) covers two $\mathrm{C}-\mathrm{X} \sigma$ bonds and one $\mathrm{X}-\mathrm{H}$ bond ( $\mathrm{X}$ represents the center of the $\mathrm{Be}-\mathrm{Be}$ bond). The combined molecular orbital picture of the three HOMO $\pi$ orbitals indicates the involvement of the $\mathrm{Be}_{2}$ orbital in the overall $\pi$ bond system. The NBO atomic charge on each beryllium atom amounts to 0.941 electron. When $\mathrm{C}$ is

substituted in two different locations of the benzene ring, they also have NBO charges close to this value (ortho, 0.512; meta, 0.970; para, 0.849 electron). The total dipole moment of $\mathrm{C} / \mathrm{Be}_{2}$ substituted benzene (calculated with aug-cc-pVTZ basis set) amounts to $0.712 \mathrm{D}$. The insertion of the second Be dimer does not change the overall picture of the bonding scheme and only little perturbation in comparison to the singly substituted benzene is observed. The substituted naphthalene molecule follows the same structural trend regardless of the position of substitution (Figure 2S, Supporting Information). Molecular orbitals and atomic charges are almost the same as those observed in the benzene case. The differences between isomers were also insignificant.

e. Extended Carbon Systems. The functionalization of carbon materials may improve their desired properties. The hydrogen storage on pure carbon materials is restricted due to very weak interactions with molecular hydrogen. The substitution of carbon atom or decoration of material with foreign chemical groups provides the direct way to enhance the adsorption properties. The investigated structures in the present section are based on the ovalene model (an extended graphene-like carbon material) (Figure 4). The carbon
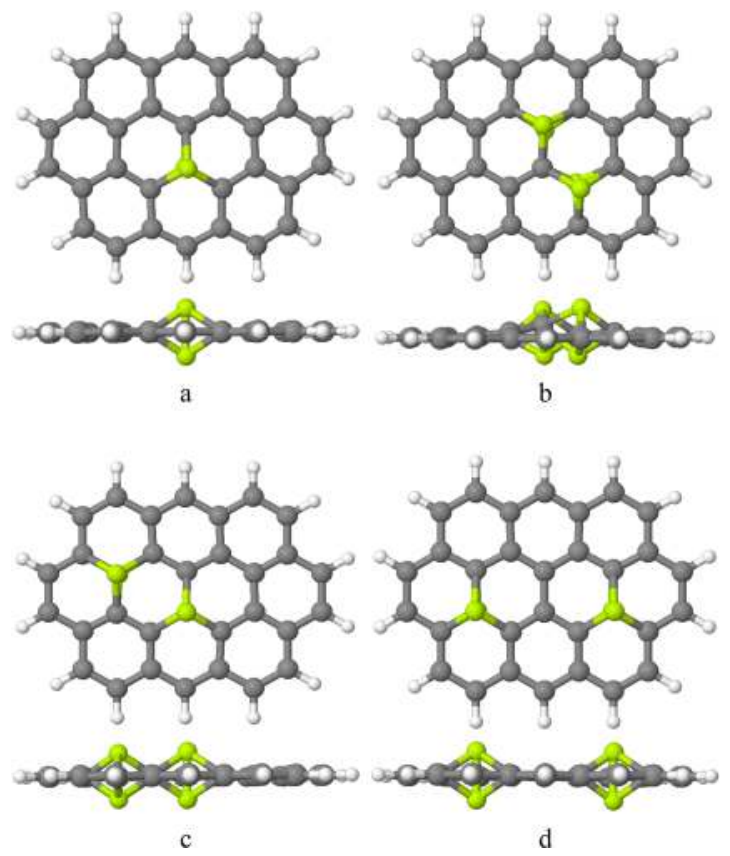

Figure 4. Structures for single and double $\mathrm{C} / \mathrm{Be}_{2}$ substitutions in the $\mathrm{C}_{32} \mathrm{H}_{14}$ ovalene base: (a) single $\mathrm{C} / \mathrm{Be}_{2}$ substitution; double (C/ $\left.\mathrm{Be}_{2}\right)\left(\mathrm{C} / \mathrm{Be}_{2}\right)$ substitutions with (b) $\mathrm{Be}_{2}-\mathrm{C}-\mathrm{Be}_{2}$, (c) $\mathrm{Be}_{2}-\mathrm{C}_{2}-\mathrm{Be}_{2}$, (d) $\mathrm{Be}_{2}-\mathrm{C}_{3}-\mathrm{Be}_{2}$ carbon separation.

substitution by $\mathrm{Be}_{2}$ leads to a similar geometrical picture like the previously discussed ethylene and aromatic compounds. The $\mathrm{Be}_{2}$ axis is perpendicular to the plane of the carbon skeleton with the midpoint of $\mathrm{Be}-\mathrm{Be}$ bond lying inside the plane. Further carbon/beryllium substitution is possible and all probable isomers of $\mathrm{Be}_{2}-\mathrm{C}_{n}-\mathrm{Be}_{2}(n=1-4)$ are considered here. Regardless of the carbon separation with respect to the beryllium centers, the structural features of these isomers correspond to the general characteristic of the fragment (vertical $\mathrm{Be}_{2}$ moiety). Only the isomer with a single carbon separation is slightly perturbed from the perfect perpendicular geometry of $\mathrm{Be}_{2}$. All $\mathrm{Be}-\mathrm{Be}$ distances in such dimers with 
doubly substituted centers are within $0.015 \AA$ with respect to the singly substituted moiety. The $\mathrm{C}-\mathrm{Be}$ bonds are also very similar in these dimers (despite different metal center positions), indicating little influence of the border effects due to the frozen external carbon ring. The picture of molecular orbitals observed for the extended $\mathrm{C}_{31} \mathrm{H}_{14} \mathrm{Be}_{2}$ complex (Figure $5)$ is similar to the aromatic compounds. The HOMO $\pi$ orbital
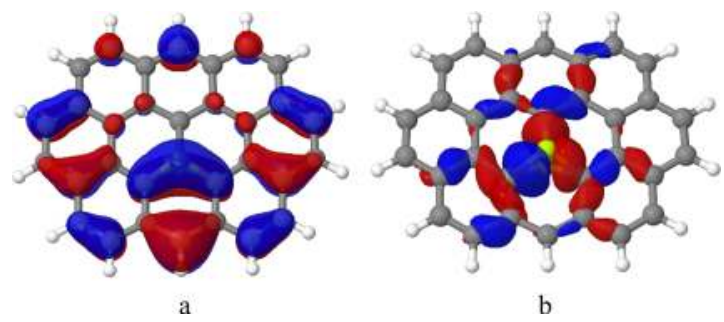

Figure 5. $\Pi$ HOMO (a) and combined three $\sigma$ HOMO molecular orbitals (b) (perspective view) of $\mathrm{C}_{31} \mathrm{H}_{14} \mathrm{Be}_{2}$ localized on the beryllium dimer.

above the $\mathrm{Be}_{2}$ center constitutes part of the extended delocalized $\pi$ system. The $\sigma$ combined orbitals representing the $\sigma \pi^{2}$ arrangement are also dipped in the sea of delocalized orbitals. The $\mathrm{Be}-\mathrm{Be}$ distance in all the cases is close to $1.73 \AA$. The comparison of all considered complexes indicates that perturbations due the $\mathrm{Be}_{2}$ insertion in the ring are almost independent when $\mathrm{Be}_{2}$ centers are separated by at least two carbon atoms. The substitution leads to the local modification of properties of original molecules as may be observed by the atomic charge distribution. The beryllium NBO charge was approximately 1.15 electron in single $\mathrm{Be}_{2}$ as well as in double substitution. More importantly, the characteristics of substitution centers (geometrical or electronic) is also similar to one observed in the single substitution. The difference in properties disappears for $\mathrm{Be}_{2}$ centers for distances larger than two carbon atoms. The local character of substitutions indicates the existence of independent active centers.

\section{CONCLUSIONS}

The doping of active carbon or nanocarbon materials is a promising direction for controlling their physical and chemical properties. In this work, the beryllium dimers were studied as potential active centers in the carbon body. $\mathrm{Be}_{2}$ represents a weakly bonded complex, with low-lying excited electronic states. These states, when activated by interaction with the "third body", lead to complexes of much higher bonding energy. The bonding in complexes results from the competition between the highly repulsive Pauli exchange energy $\left(\varepsilon_{\mathrm{ex}}^{\mathrm{HL}}\right)$ and the attractive interaction energy terms $\left(\varepsilon_{\mathrm{el}}^{(10)}, \Delta E_{\mathrm{del}}^{\mathrm{HF}}, \varepsilon_{\mathrm{disp}}^{(20)}\right)$. The values of separate contributions are comparable to those characterizing chemical bonds. Although in $\mathrm{CH}_{2} \mathrm{Be}_{2} \mathrm{H}_{2}$, the $\mathrm{Be}-\mathrm{Be}$ distance is significantly shortened due to the interactions with the environment, the molecular orbital picture of the valence space $\left(\sigma_{\mathrm{g}} \sigma_{\mathrm{u}} \pi_{\mathrm{u}} \sigma_{\mathrm{g}}\right)$ is preserved and constitutes the basis for the MO formation in larger systems. The substitution of single carbon by the pair of beryllium atoms does not destroy planarity and the aromaticity of the carbon network. The inclusion of $\mathrm{Be}_{2}$ in the place of carbon preserves the symmetry characteristics of complex with axis of $\mathrm{Be}_{2}$ being perpendicular to carbon network with the midpoint $\mathrm{X}$ of $\mathrm{Be}-\mathrm{Be}$ bond located in the original carbon position (i.e., plane of the ring). The position of hydrogen (or hydrogens), originally attached to the replaced carbon is also preserved. This phenomenon was observed in all studied systems where substituted carbon possessed the $\mathrm{sp}^{2}$ character. The midpoint $\mathrm{X}$ of $\mathrm{Be}_{2}$ may be considered as a "pseudo $\mathrm{sp}^{2}$ carbon atom" with $\sigma \pi^{2}$ orbital organization of valence orbitals-an analogue to the atomic $\mathrm{sp}^{2}$ case. The molecular orbital pictures, presented for ethylene, benzene, naphthalene, and ovalene derivatives, confirm the proposed model. The $\sigma_{\mathrm{g}}$ orbital of $\mathrm{Be}_{2}$ is included in the sea of $\pi$ molecular orbitals of conjugated molecules (in analogy to the $\mathrm{p}_{z}$ atomic orbital in carbon systems). The perturbations due to the doping were found to possess the local character and may be considered in larger systems as chemically active centers. The positive atomic charges on beryllium atoms are large and shortening of the bond can be attributed to the $\mathrm{Be}_{2}{ }^{+}$fragment. The results of population analysis should be treated with caution, however, due to the extensively delocalized character of electronic density.

\section{ASSOCIATED CONTENT}

\section{S Supporting Information}

Optimized structures of $\mathrm{CH}_{2} \mathrm{Be}_{2} \mathrm{H}_{2}$ and $\mathrm{CH}_{2} \mathrm{CH}_{2}$ and views of $\mathrm{Be}_{2}$-substituted benzene and naphthalene derivatives.

\section{AUTHOR INFORMATION}

\section{Corresponding Authors}

Email: szczepan.roszak@pwr.edu.pl (S.R).

Email: devashis@icnanotox.org (D.M.).

Email: jerzy@icnanotox.org (J.L.).

\section{Notes}

The authors declare no competing financial interest.

\section{ACKNOWLEDGMENTS}

This work has been supported by the PREM (Award No. DMR-1205194) and ONR (Award No. N00014-13-1-0501) grants. S.R. acknowledges the financial support by a statutory activity subsidy from the Polish Ministry of Science and Technology of Higher Education for the Faculty of Chemistry of Wroclaw University of Technology and NCN grant No. 2012/07/B/ST4/01584. We also thank the Mississippi Center for Supercomputing Research, Wroclaw and Poznan Centers for Networking and Supercomputing, and Interdisciplinary Center for Mathematical Modeling of Warsaw University for providing generous computer time.

\section{REFERENCES}

(1) Advanced Inorganic Chemistry; Cotton, F. A., Wilkinson, G., Murillo, C. A., Bochmann, M., Eds.; Wiley: New York, 1999.

(2) Steenland, M. C.; Ward, E. Lung Cancer Incidence Among Patients with Beryllium Disease: A Cohort Mortality Study. J. Natl. Cancer Inst. 1991, 83, 1380-1385.

(3) Kuchta, B.; Firlej, L.; Roszak, S.; Pfeifer, P. A Review of Boron Enhanced Nanoporous Carbons for Hydrogen Adsorption: Numerical Perspective. Adsorption 2010, 16, 413-421.

(4) Porter, W. W., III; Wong-Foy, A.; Dailly, A.; Matzger, A. J. Beryllium Benzene Dicarboxylate: The First Beryllium Microporous Coordination Polymer. J. Mater. Chem. 2009, 19, 6489-6491.

(5) Sumida, K.; Hill, M. R.; Horike, S.; Dailly, A.; Long, J. R. Synthesis and Hydrogen Storage Properties of Be-12(OH)(12) (1,3,5benzenetribenzoate)(4). J. Am. Chem. Soc. 2009, 131, 15120-15121.

(6) Han, S. S.; Deng, W. Q.; Goddard, W. A. Improved Designs of Metal-Organic Frameworks for Hydrogen Storage. Angew. Chem., Int. Ed. 2007, 46, 6289-6292. 
(7) Kim, Y.-H.; Zhao, Y.; Williamson, A.; Heben, M. J.; Zhang, S. B. Nondissociative Adsorption of $\mathrm{H}_{2}$ Molecules in Light-Element-Doped Fullerenes. Phys. Rev. Lett. 2006, 96, 016102.

(8) Koch, W.; Frenking, G.; Gauss, J.; Cremer, D.; Sawaryn, A.; Schleyer, P. v. R. Structures, Stabilities, and Bonding in $\mathrm{CBe}_{2}, \mathrm{C}_{2} \mathrm{Be}$, and $\mathrm{C}_{2} \mathrm{Be}_{2}$. J. Am. Chem. Soc. 1986, 108, 5732-5737.

(9) Patrick, A. D.; Williams, P.; Blaisten-Barojas, E. J. Energetics and Bonding in Beryllium Metallized Carbon Clusters. Mol. Struct. Teochem 2007, 824, 39-47.

(10) Ghouri, M. M.; Yareeda, L.; Mainardi, D. S. Geometry and Stability of $\mathrm{Be}_{\mathrm{n}} \mathrm{C}_{\mathrm{m}}(\mathrm{n}=1-10 ; \mathrm{m}=1,2, \ldots$, to $11-\mathrm{n})$ Clusters. J. Phys. Chem. A 2007, 111, 13133-13147.

(11) Heaven, M. C.; Merritt, J. M.; Bondybey, V. E. Bonding in Beryllium Clusters. Annu. Rev. Phys. Chem. 2011, 62, 375-393.

(12) Le Roy, R. J.; Dattani, N. S.; Coxon, J. A.; Ross, A. J.; Crozet, P.; Linton, C. Accurate Analytic Potentials for $\mathrm{Li}_{2}\left(\mathrm{X}^{1} \Sigma^{+}{ }_{\mathrm{g}}\right)$ and $\mathrm{Li}_{2}\left(\mathrm{~A} 1 \Sigma^{+}{ }_{\mathrm{u}}\right)$ from 2 to $90 \AA$, and the Radiative Lifetime of $\operatorname{Li}(2 \mathrm{p})$. J. Chem. Phys. 2009, 131, 204309.

(13) Tang, K. T.; Toennies, J. P. The van der Waals Potentials Between All the Rare Gas Atoms from He to Rn. J. Chem. Phys. 2003, 118, 4976-4983.

(14) Verhaegen, G.; Drowart, J. Mass Spectrometric Determination of the Heat of Sublimation of Boron and of the Dissociation Energy of $\mathrm{B}_{2}$. J. Chem. Phys. 1962, 37, 1367-1368.

(15) Kaplan, I. G.; Roszak, S.; Leszczynski, J. Nature of Binding in the Alkaline-Earth Clusters: $\mathrm{Be}_{3}, \mathrm{Mg}_{3}$, and $\mathrm{Ca}_{3}$. J. Chem. Phys. 2000, 113, 6245-6252.

(16) Moore, C. E. Tables of Spectra of Hydrogen, Carbon, Nitrogen and Oxygen Atoms and Ions in CRC Series in Evaluated Data in Atomic Physics; Gallagher, J. W., Ed.; CRC Press: Boca Raton, FL1993.

(17) Møller, C.; Plesset, M. Note on an Approximation Treatment for Many-Electron Systems. Phys. Rev. 1934, 46, 618-622.

(18) Woon, D. E.; Dunning, T. H., Jr. Gaussian Basis Sets for Use in Correlated Molecular Calculations. IV. Calculation of Static Electrical Response Properties. J. Chem. Phys. 1994, 100, 2975-2988.

(19) Dunning, T. H., Jr. Gaussian Basis Sets for Use in Correlated Molecular Calculations. I. The Atoms Boron Through Neon and Hydrogen. J. Chem. Phys. 1989, 90, 1007-1023.

(20) Parr, R. G.; Yang, W. Density-Functional Theory of Atoms and Molecules; Oxford University Press: New York, 1994.

(21) Becke, A. D. Density-Functional Thermochemistry. III. The Role of Exact Exchange. J. Chem. Phys. 1993, 98, 5648-5652.

(22) Vosko, S. H.; Wilk, I.; Nusiar, M. Accurate Spin-Dependent Electron Liquid Correlation Energies for Local Spin Density Calculations: A Critical Analysis. Can. J. Phys. 1980, 58, 1200-1211.

(23) Lee, C.; Yang, W.; Parr, R. G. Development of the Colle-Salvetti Correlation-Energy Formula into a Functional of the Electron Density. Phys. Rev. B 1988, 37, 785-789.

(24) Góra, R. W.; Bartkowiak, W.; Roszak, S.; Leszczynski, J. Intermolecular Interactions in Solution: Elucidating the Influence of the Solvent. J. Chem. Phys. 2004, 120, 2802-2813.

(25) Boys, S. F.; Bernardi, F. The Calculation of Small Molecular Interactions by the Differences of Separate Total Energies. Some Procedures with Reduced Errors. Mol. Phys. 2002, 100, 65-73.

(26) Reed, A. E.; Weinstock, R. B.; Weinhold, F. Natural Population Analysis. J. Chem. Phys. 1985, 83, 735-746.

(27) Frisch, M. J.; Trucks, G. W.; Schlegel, H. B.; Scuseria, G. E.; Robb, M. A.; Cheeseman, J. R.; Scalmani, G.; Barone, V.; Mennucci, B.; Petersson, G. A.; et al. Gaussian 09, Revision A.1; Gaussian, Inc.: Wallingford, CT, 2009.

(28) Schmidt, M. W.; Baldridge, K. K.; Boatz, J. A.; Elbert, S. T.; Gordon, M. S.; Jensen, J. H.; Koseki, S.; Matsunaga, N.; Nguyen, K. A.; $\mathrm{Su}, \mathrm{S}$. J.; et al. General Atomic and Molecular Electronic Structure System. J. Comput. Chem. 1993, 14, 1347-1363.

(29) Gora, R. W. EDS Package, V.2.8.3, Wroclaw, Poland, 19992009.

(30) Jmol: An Open-Source Java Viewer for Chemical Structures in 3D, http://jmol.sourceforge.net/.
(31) Bruna, P. J.; Wright, J. S. Strongly Bound Doubly Excited States of $\mathrm{Be}_{2}$. Can. J. Chem. 1996, 74, 998-1004.

(32) Bruna, P. J.; Meng, B.; Wright, J. S. Importance of Strongly Bound Excited States in the Electronic Spectrum of $\mathrm{Be}^{+}{ }_{2}$. J. Mol. Spectrosc. 1993, 159, 79-95. 